\title{
Aging Does Not Affect Axon Initial Segment Structure and Somatic Localization of Tau Protein in Hippocampal Neurons of Fischer 344 Rats
}

\author{
(1)Andrew Kneynsberg, ${ }^{1,2}$ and ${ }^{-}$Nicholas M. Kanaan ${ }^{1,2,3}$ \\ DOI:http://dx.doi.org/10.1523/ENEURO.0043-17.2017 \\ ${ }^{1}$ Neuroscience Program, Michigan State University, East Lansing, MI 48824, ${ }^{2}$ Department of Translational Science \\ and Molecular Medicine College of Human Medicine, Michigan State University, Grand Rapids, MI 49503, and \\ ${ }^{3}$ Hauenstein Neuroscience Center, Mercy Health Saint Mary's, Grand Rapids, MI 49503
}

\begin{abstract}
Little is known about the specific contributions of aging to the neuron dysfunction and death in Alzheimer's disease (AD). $A D$ is characterized by the pathological accumulation of abnormal tau (a microtubule-associated protein), and the mislocalization of tau from the axon to the somatodendritic compartment is thought to play an important role in disease pathogenesis. The axon initial segment (AIS) is thought to play a role in the selective localization of tau in the axonal compartment. Thus, disruption in the AIS barrier may allow tau to diffuse freely back into the somatodendritic compartment and potentially lead to neurotoxicity. Here, we analyzed AISs using stereological methods and protein immunoblotting, and the localization of tau was assessed with immunofluorescence optical density measurements and protein immunoblotting. None of the outcome measurements assessed, including AIS structure, AIS protein levels, the distribution of tau in neurons of the hippocampus (HP), and total tau or phospho-tau protein levels were different in young, middle-, and old-age Fischer 344 rats. The outcome measurements assessed, including AIS structure, AIS protein levels, the distribution of tau in neurons of the HP, and total tau or phospho-tau protein levels were not different in young, middle-, and old-age Fischer 344 rats, with the exception of a small reduction in AIS volume and diameter in the CA2 region of aged animals. These data suggest that aging largely has no effect on these properties of the AIS or tau distribution, and thus, may not contribute directly to tau mislocalization.
\end{abstract}

Key words: aging; Alzheimer's disease; ankyrin G; axon initial segment; Fischer 344; tau

\section{Significance Statement}

Aging is a primary risk-factor for $A D$, but the events during aging that contribute to the development of disease are unknown. In healthy neurons, the tau protein is enriched in the axon, a distribution facilitated, at least in part, by the axon initial segment (AIS). Tau accumulation in the cell body due to disruption of the AIS barrier is potentially a contributing factor to AD pathogenesis. Very little is known about the effects of normal aging on AIS proteins or levels and localization of tau. Here, we report that there were no changes in the AIS or tau localization with increasing age in rats, suggesting disease-specific effects may drive changes in these factors during $A D$ pathogenesis.

\section{Introduction}

Alzheimer's disease (AD) is the most prevalent neurodegenerative disease of individuals over the age of 65 , and affects over 6.4 million adults in the United States

Received February 6, 2017; accepted June 29, 2017; First published July 07, 2017.

The authors declare no competing financial interests.
(James et al., 2014). The leading risk factor for developing the disease is aging, and while the cause of $A D$ is still unclear, the accumulation of inclusions comprised of tau protein is a hallmark of the disease (Santuccione et al., 
2013). It remains unclear whether changes in the distribution of tau that are reminiscent of AD-related changes, such as accumulation in the somatodendritic compartment, occur during normal aging. Aged Fischer 344 rats are commonly used for aging research and exhibit agerelated behavioral deficits of learning and memory as well as motor impairment (Spangler et al., 1994; van der Staay and Blokland, 1996; Cochran et al., 2014). Additionally, aging causes altered neuronal protein expression, axonal atrophy, and some gliosis in the F344 rat model (Parhad et al., 1995). For example, glial fibrillary acidic protein (GFAP) is shown to increase significantly in the hippocampus (HP) of aged rats both with and without cognitive impairment (VanGuilder et al., 2011). Thus, Fischer 344 rats are a good model to recapitulate factors of human aging (van der Staay and Blokland, 1996) and determining whether aging effects the AIS and tau distribution. The underlying hypothesis is that aging causes alterations in AIS integrity and tau mislocalization, which may represent events that contribute to aging as a strong risk factor for $A D$.

Tau, a microtubule-associated protein, is thought to contribute to the development and progression of $A D$ pathology, but the mechanisms behind tau toxicity remain largely unknown. Age-related accumulations of tau were reported in some nonhuman primate brains (Oikawa et al., 2010; Perez et al., 2013), yet systematic analysis of the cellular localization of tau accumulation across aging is not well studied. Unfortunately, human tissue studies are often limited in scope across age groups making it hard to appreciate changes from young to old age. In healthy neurons, tau is enriched in the axonal compartment, where it may stabilize microtubules and play a role in regulating axonal functions such as transport (Tytell et al., 1984; Binder et al., 1986; Kanaan et al., 2013). The redistribution of tau from the axonal compartment to the somatodendritic compartment is thought of as an important event in tau-mediated neurotoxicity (Buee et al., 2000). The preferential localization of tau in axons is mediated, at least in part, by the axon initial segment (AIS), which acts as a retrograde barrier for freely diffusing tau (Li et al., 2011; Sun et al., 2014; Zempel and Mandelkow, 2014; Sohn et al., 2016).

Importantly, very little is known about the connections between aging, the AIS, and tau distribution. The AIS is a selective diffusion barrier separating the axonal compartment from the somatodendritic compartment (Winckler

This work was supported by the NIH/NIA Grant R01 AG044372 (to N.M.K.), the Jean P. Schultz Biomedical Research Endowment (N.M.K.), and Secchia Family Foundation Research Fund (N.M.K.)

Acknowledgements: We thank Dr. Vann Bennett at Duke University for his assistance and technical expertise with the AnkG immunoblots.

Correspondence should be addressed to Andrew Kneynsberg, Neuroscience Program, Department of Translational Science and Molecular Medicine, Michigan State University, Grand Rapids, Ml 49503, E-mail: kneynsbe@msu.edu.

DOI:http://dx.doi.org/10.1523/ENEURO.0043-17.2017

Copyright @ 2017 Kneynsberg and Kanaan

This is an open-access article distributed under the terms of the Creative Commons Attribution 4.0 International license, which permits unrestricted use, distribution and reproduction in any medium provided that the original work is properly attributed. et al., 1999). The establishment of the AIS creates a filter that regulates intracellular traffic based on protein size or the type of motor proteins carrying cargo along microtubules (Song et al., 2009; Leterrier and Dargent, 2014). Ankyrin $\mathrm{G}$ (AnkG) is well established as a necessary protein for the development and maintenance of the AIS as a selective filter, as well as a necessary protein for developing and maintaining axonal polarity (Zhou et al., 1998; Hedstrom et al., 2008). AnkG also has an integral role in recruiting and binding structural proteins to the AIS, such as $\beta$ IV-spectrin and neurofascin (Hedstrom et al., 2007; Freal et al., 2016). Interestingly, a single previous report showed that some structural proteins in the AIS (specifically ankyrin) are reduced with age in wild-type mice (Bahr et al., 1994). Thus, we set out to determine if the structure of the AIS and/or tau localization is altered during normal aging. Our data show that AIS structure, levels of multiple AIS proteins, and the distribution of tau in HP neurons are not altered with advancing age in Fischer 344 rats.

\section{Materials and Methods}

\section{Animals}

Young adult (4 months), middle-aged (14 months) and aged (24 months) male Fischer 344 rats were used for all experiments. Six animals per age group $(n=6)$ were used to obtain fixed tissue for histologic analysis while five or six animals $(n=5-6)$ per age group were used for fresh brain homogenate. The animals were provided rat chow and water ad libitum and housed in a reverse light-dark cycle room. All animal studies were performed in accordance with standard regulations and were approved by the Michigan State University Institutional Animal Care and Use and Committee.

\section{Tissue processing}

Animals used for collection of fresh brain tissue were transcardially perfused with $200 \mathrm{ml}$ of $0.9 \%$ saline containing heparin $(10,000 \mathrm{U} / \mathrm{l})$. The brains were extracted and the HP was dissected and frozen on dry ice. For collection of fresh tissue for AnkG immunoblotting, animals were perfused for 5 min with saline containing heparin $(\sim 60 \mathrm{~mL})$. The extracted HPs were then immediately frozen in liquid nitrogen and stored in liquid nitrogen until processing for AnkG immunoblotting. To collect fixed tissue, the saline perfusion was followed by $200 \mathrm{ml}$ phosphate buffered $4 \%$ paraformaldehyde. The brains were postfixed in $4 \%$ paraformaldehyde for $24 \mathrm{~h}$. After postfixation, the brains were embedded into gelatin blocks for sectioning (Smiley and Bleiwas, 2012). The gelatin block was equilibrated in $20 \%$ glycerol. The gelatin block was cut into $40-\mu \mathrm{m}$-thick coronal sections on a freezing, sliding stage microtome. Sections were stored in cyroprotectant until processed for immunohistochemistry or immunofluorescence.

\section{Immunoblotting}

Tissue from the HP was homogenized in $300 \mu \mathrm{l}$ of 10 $\mathrm{mM}$ Tris, $1 \mathrm{mM}$ EDTA, $0.8 \mathrm{mM} \mathrm{NaCl}$, and $10 \%$ sucrose buffer containing protease and phosphatase inhibitors (10 
$\mu \mathrm{g} / \mathrm{ml}$ pepstatin, $10 \mu \mathrm{g} / \mathrm{ml}$ leupeptin, $10 \mu \mathrm{g} / \mathrm{ml}$ bestatin, $10 \mu \mathrm{g} / \mathrm{ml}$ aprotinin, $1 \mathrm{mM}$ PMSF, $10 \mathrm{mM} \beta$-glycerophosphate, $1 \mathrm{mM}$ sodium orthovanadate, $10 \mathrm{mM}$ sodium fluoride, and $1 \mathrm{mM}$ tetra-sodium pyrophosphate decahydrate), using a sonicator (XL-2000, Misonix, $10 \times 1 \mathrm{~s}$ bursts at power level 1). Lysates were cleared of cellular debris by centrifugation at $22,000 \times g$ for 20 min at $4^{\circ} \mathrm{C}$. The resulting supernatants were collected for analysis and the total protein content was assessed using the Bradford protein assay (B6916, Sigma). The samples were diluted in Laemmli buffer and heated to $95^{\circ} \mathrm{C}$ for $10 \mathrm{~min}$. Lysate samples separated using SDS-PAGE (50 $\mu \mathrm{g}$ total protein/ lane for AIS proteins; $20 \mu \mathrm{g} / \mathrm{lane}$ for tau protein) on $4-20 \%$ Criterion TGX (Bio-Rad) gradient gels at $250 \mathrm{~V}$ and transferred to nitrocellulose membranes for 50 min (66458; Pall Life Sciences) to quantify the amount of AIS proteins and tau between age groups ( $n=5$ /group).

Because of the large size of the AnkG protein, a blotting protocol optimized for large molecular weight proteins was used (Fairbanks et al., 1971; Davis and Bennett, 1982; Bolt and Mahoney, 1997). The flash frozen HPs were dropped into nine volumes of urea buffer (8 M urea, $5 \%$ SDS, $5 \mathrm{mM}$ N-ethyl maleimide, $10 \mathrm{mM}$ HEPES, 10 $\mu \mathrm{g} / \mathrm{ml}$ leupeptin, and $10 \mu \mathrm{g} / \mathrm{ml}$ pepstatin) at $65^{\circ} \mathrm{C}$ and immediately pulverized with an Eppendorf tube pestle (\#12-141-363, Thermo Fisher) for $10 \mathrm{~s}$ and then sonicated, as described above. The samples were then diluted in Laemmli buffer and heated to $95^{\circ} \mathrm{C}$ for $10 \mathrm{~min}$. The protein concentrations of the resulting lysate samples were measured using the SDS Lowry protein assay as described (Cox et al., 2016). Lysate samples (100 $\mu \mathrm{g} / \mathrm{lane}$; $n=6 /$ group) were separated using SDS-PAGE on 3-8\% Criterion XT Tris-Acetate in XT buffer (Bio-Rad) gradient gels at $150 \mathrm{~V}$ and transferred to nitrocellulose membranes in transfer buffer [ $40 \mathrm{mM}$ Tris, $20 \mathrm{mM}$ sodium acetate, 2 mM EDTA, pH 7.4, 20\% (v/v) methanol, 0.05\% (w/v) SDS] for $120 \mathrm{~min}$ at $10 \mathrm{~V}$. After transferring, the blots were stained with Ponceau S [0.04\% (w/v) Ponceau S (\#P3504, Sigma), $0.1 \%(\mathrm{v} / \mathrm{v}$ ) acetic acid] for $5 \mathrm{~min}$ followed by $2 \times$ 5 min washes in $5 \%$ acetic acid $(\mathrm{v} / \mathrm{v})$ and then two washes in water. The blots were imaged before proceeding to blocking and Ponceau bands were used to normalize the quantified AnkG signals.

All membranes were blocked in $2 \%$ nonfat dry milk in Tris-buffered saline (NFDM-TBS; Tris $50 \mathrm{mM}$ and $\mathrm{NaCl}$ $150 \mathrm{mM}, \mathrm{pH}$ 7.4) for $1 \mathrm{~h}$ at room temperature and incubated with primary antibody in NFDM-TBS overnight at $4^{\circ} \mathrm{C}$. Blots were probed with AnkG antibody $(\mathrm{H}-215$, Santa Cruz sc-28561, 1:2000), $\beta$ IV-spectrin (NeuroMab \#75$377,1: 1000$ ), neurofascin (NeuroMab \#75-172 1:1000), SMI312 (abcam, ab24574, 1:20,000), R1 (1:100,000; Berry et al., 2004), Tau7 (1:500,000; Horowitz et al., 2006), AT8 (phospho-Ser199/Ser202/Thr205, 1:10,000), PHF-1 (phosphoSer396/Ser404, 1:50,000), phospho-Ser422 (1:2000), $\beta$ IIItubulin antibody (Tuj1, 1:10,000; Caccamo et al., 1989), GFAP (G3893 Sigma, 1:2000), and loading control glyceraldehyde 3-phosphate dehydrogenase (GAPDH; Cell Signaling, 5174, 1:2000). After incubation with primary antibodies, the membranes were washed in TBS and $0.1 \%$ Tween 20 and incubated in appropriate species- specific IRDye $680 \mathrm{RD}$ or $800 \mathrm{CW}$ secondary antibodies (1:20,000 in NFDM-TBS; LI-COR Biotechnology). The membranes were washed and the reactivity visualized with a LI-COR Odyssey infrared imager. The signal intensity for each band was quantified using the LI-COR Image Studio software (v5.2) and signal intensities for AIS proteins or tau are expressed as a ratio to GAPDH signal intensities. AnkG 270 and $480 \mathrm{kDa}$ are expressed as a ratio of the Ponceau $S$ intensity of a protein band at $\sim 200$ $\mathrm{kDa}$. The intensities of GAPDH and Ponceau that were used as loading controls for normalization of immunoblotting signals were not changed across age $\left[\mathrm{GAPDH}, F_{(2,12)}\right.$ $=0.001261, p=0.9987$ (Fig. $1 L$ ); Ponceau $\mathrm{S}, F_{(2,15)}=$ 1.322, $p=0.2959$ (Fig. 1C)].

\section{Immunohistochemistry and immunofluorescence}

A one in six series of tissue sections were processed for each age group $(n=6)$ for immunohistochemical detection of AnkG. The tissue was rinsed in 0.1 M TBS, pH 7.4, containing $0.5 \%$ Triton X-100 (TBS-Tx) six times for 10 min each. The tissue was then incubated in $3 \% \mathrm{H}_{2} \mathrm{O}_{2}$ in TBS-Tx for $1 \mathrm{~h}$ at room temperature to quench endogenous peroxidase activity, and then rinsed again. An avidin/ biotin blocking kit (Vector Labs SP-2001) was used to block endogenous avidin in the gelatin matrix. Nonspecific antibody binding was inhibited by incubating the tissue in blocking buffer [10\% goat serum (GS)/2\% bovine serum albumin/0.5\% TBS-Tx] for $1 \mathrm{~h}$ at room temperature. The tissue was then incubated over night at $4^{\circ} \mathrm{C}$ with rabbit anti-AnkG primary antibody $(\mathrm{H}-215$, Santa Cruz sc-28561) 1:1000 in dilution buffer (2\%GS and 0.5\% TBS$\mathrm{Tx})$. The tissue was rinsed $(6 \times 10 \mathrm{~min}$ in $0.5 \%$ TBS-Tx) and incubated for $2 \mathrm{~h}$ in biotinylated goat anti-rabbit secondary antibody (BA-1000, Vector) at a concentration of 1:500 in dilution buffer. The tissue was then rinsed again and incubated in avidin-biotin complex (ABC) solution (PK-6100, Vector) for 1 hour. The $A B C$ solution contained $50 \mu \mathrm{l}$ of solution A and $50 \mu \mathrm{l}$ of solution B in $10 \mathrm{ml}$ of TBS made according to the manufacturer's instructions. After rinsing the tissue, the staining was developed using 3,3'-diaminobenzidine (D5637, Sigma) solution (50 $\mathrm{mg} / \mathrm{ml}, 0.5 \%$ TBS-Tx, and $0.003 \% \mathrm{H}_{2} \mathrm{O}_{2}$ ) for $12 \mathrm{~min}$. The tissue was then rinsed, mounted on microscope slides, and coverslipped with CYTOSEAL 60 (\#8310-16, Thermo Scientific).

A one in six series of tissue sections ( $n=6 /$ group) was used for the immunofluorescent labeling of tau. All tissue was stained simultaneously in staining dishes using the same reagents. Nonspecific antibody binding was inhibited by incubating the tissue in blocking buffer (10\% GS, $2 \%$ bovine serum albumin, and $0.5 \%$ TBS-Tx) for $1 \mathrm{~h}$ at room temperature. The tissue was then incubated over night at $4^{\circ} \mathrm{C}$ with mouse anti-tau primary antibody (Tau7; $1: 3500$ ) in dilution buffer (2\%GS and $0.5 \%$ TBS-Tx). The tissue was rinsed $(6 \times 10 \mathrm{~min}$ in $0.5 \%$ TBS-Tx $)$ and incubated for $2 \mathrm{~h}$ in Alexa Fluor 488-conjugated goat anti-mouse $\lg G(\mathrm{H}+\mathrm{L}$; \#A-11001, Thermo Fisher) at a concentration of 1:500 in dilution buffer. The tissue was then incubated in DAPI $(0.5 \mu \mathrm{g} / \mathrm{ml}$ in $0.5 \%$ TBS-Tx for 10 $\mathrm{min})$, rinsed $(5 \times 10 \mathrm{~min}$ in $0.5 \% \mathrm{TBS}-\mathrm{Tx})$, and the sec- 
A

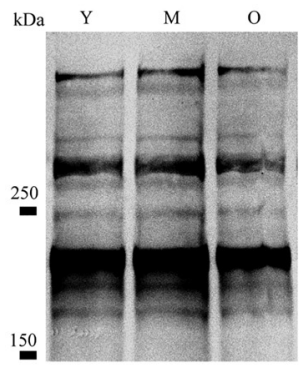

D
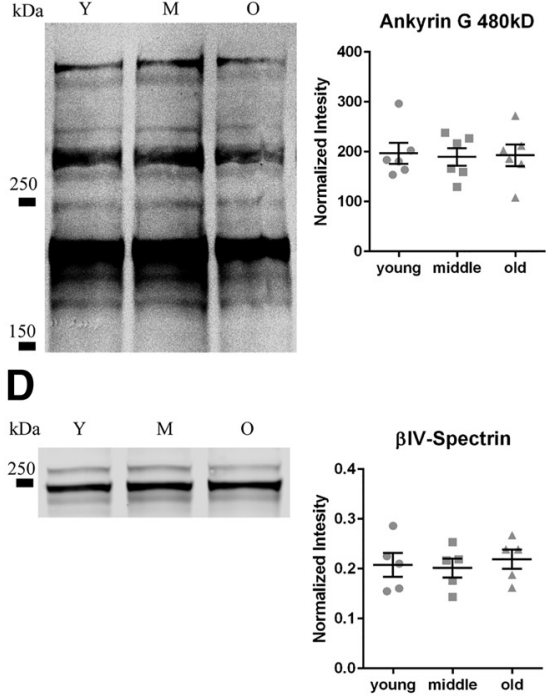

B

E

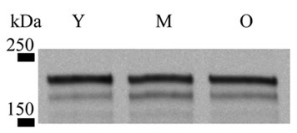

H

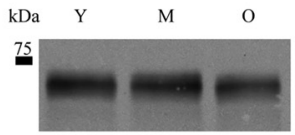

K

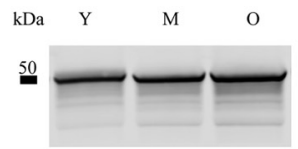

C

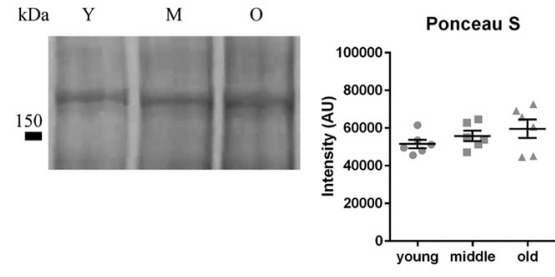

F
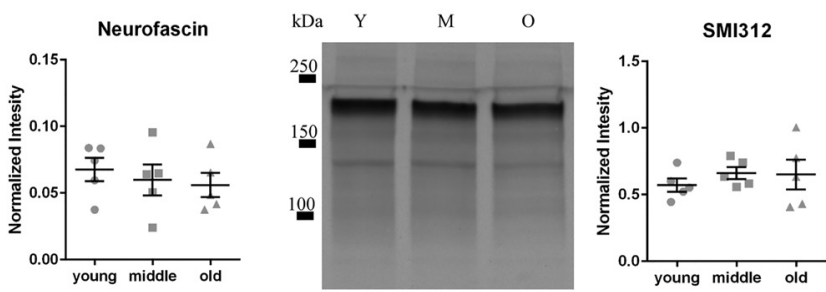

I
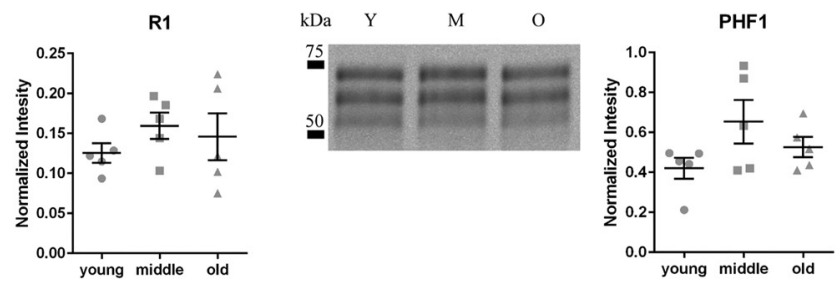

L
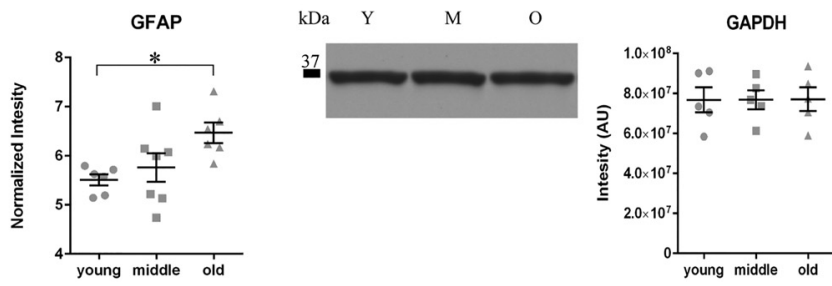

Figure 1. Aging does not alter levels of AIS proteins, total tau, and phosphorylated tau proteins. $\boldsymbol{A}, \boldsymbol{B}$, Amount of $480-\mathrm{kDa}(A)$ and $270-\mathrm{kDa}(B)$ isoforms of AnkG do not change between young, middle, and old rats. Note that the other isoforms of AnkG not analyzed are isoforms that are not AIS-specific. $\boldsymbol{C}$. AnkG Western blottings were normalized to Ponceau $\mathbf{S}(\boldsymbol{C})$ staining for loading control. $\boldsymbol{D}, \boldsymbol{E}$, The amount of $\beta \mathrm{IV}$-spectrin $(\boldsymbol{D})$ and neurofascin $(\boldsymbol{E})$ also remain unchanged during aging in rats. $\boldsymbol{F}$, The level of axonal neurofilaments, as indicated by the SMI-312 antibody. The SMI-312 antibody is an axonal marker that labels phospho-neurofilaments in axons. SMI-312 levels are not changed with age, confirming that total axon content is similar across age groups. $\boldsymbol{G}, \boldsymbol{H}$, The total level of tau detected with Tau7 $(\boldsymbol{G})$ and polyclonal R1 $(\boldsymbol{H})$ do not change with age in the rat HP. $\boldsymbol{I}$, The levels of PHF1, a phospho-epitope of tau, are not changed with age. $\boldsymbol{J}$, The total levels of microtubules, labeled with $\beta$ III-tubulin, remained unchanged with advancing age. $K$, GFAP, an astrocytic marker known to increase with age, is significantly increased in the HP of old age rats compared to young and middle aged rats; one-way ANOVA, Tukey's post hoc, $* p<0.05$. $\boldsymbol{L}$, Western blot band intensities are normalized to GAPDH, which did not change with age. All data are displayed as mean \pm SEM.

tions were mounted on microscope slides. To block endogenous autofluorescence, the tissue was treated with Sudan black. The slides were incubated in $70 \%$ ethanol for $2 \mathrm{~min}$, then in a saturated solution of Sudan Black B (Fisher, \#AC419830100) for 5 min. The slides were then differentiated in $70 \%$ ethanol until background (gray matter) was pale gray, and rinsed in $\mathrm{dH}_{2} \mathrm{O}(2 \times 3 \mathrm{~min})$. The slides were then coverslipped using Vectashield hardset mountant (H-1400, Vector; Kanaan et al., 2008).

\section{Stereology}

The spaceballs stereological probe is an unbiased and systematic stereological sampling method to estimate the total length of a population of fibers in 3D space, and this probe was used to quantify AIS length in the HP of rats. This stereological method was performed using serial sections (one in six series). Sampling grids (i.e., CA: $500 \times$ $500 \mu \mathrm{m}$; DG: $200 \times 500 \mu \mathrm{m}$ ) were chosen for each region to allow for $\sim 200$ fiber intersections to be counted in the 
HP for each hemisphere and to yield a Gunderson coefficient of error $<0.1$ for all samples. The mean coefficient of error was $0.058 \pm 0.001$ (SEM). A hemisphere probe with a radius of $11 \mu \mathrm{m}$ was used to sample sites throughout the HP. The mean measured tissue thickness was $\sim 13-14 \mu \mathrm{m}$. A $4 \times$ objective was used to outline each region and a $60 \times$ oil objective lens (1.35 numerical aperture) was used for all stereological counts.

The AutoNeuron probe in Neurolucida (MBF Bioscience) was used to acquire measurements of individual AIS length, volume and diameter in the regions of the HP (CA1, CA2, CA3 and dentate gyrus) in young, middle, and old aged animals. In each region, an image stack was acquired with a $60 \times$ oil objective lens through the complete depth of each section at a step-size of $0.5 \mu \mathrm{m}$. A 3D representation of each individual AIS in the HP was created in the software using the following settings for AutoNeuron: image type, brightfield; max process diameter, $2.00 \mu \mathrm{m}$; $X Y$ region, all; $Z$ range, all; trace somas, no; soma sensitivity, 50; min soma diameter, $2.00 \mu \mathrm{m}$; seed detection sensitivity, 70; seed response filter, 4; tracing sensitivity, 60; tolerance to gaps, low; and connect branches, no. These settings were chosen to best detect the AIS of each neuron, while not falsely detecting background tissue stain or failing to differentiate individual AISs.

\section{Cellular protein quantification}

The tau immunofluorescence-stained tissue was imaged on a Nikon Al confocal system and a Nikon Eclipse Ti microscope with a $40 \times$ oil objective (1.30 numerical aperture). Image stacks (0.5 $\mu \mathrm{m}$ step size) were acquired of neurons in each HP region (CA1, CA2, CA3, and the dentate gyrus) using acquisition settings in the linear range of fluorescent intensity without saturation of tau signal and the same acquisition settings were used for all animals. Four image stacks were acquired per animal. The neurons were analyzed with NIS Elements (v4.30, Advanced Research, Nikon). The average intensity of Tau7 immunofluorescent signal was measured in the soma of individual pyramidal neurons in all CA regions (CA1, CA2, and $\mathrm{CA} 3$ ). Cells were chosen as randomly as possible, but only cells with an entire cross-section through the middle of the cell (i.e., the z-slice with the largest nuclear width) within the acquired z-stack and without overlapping cell bodies were used for analysis. To increase the rigor of this analysis, the experimenter was blinded to the condition of the samples. A box $\left(\sim 8-12 \mu \mathrm{m}^{2}\right)$ was drawn as large as possible inside the somatic compartment of each neuron, excluding the DAPI-positive nuclei. The mean value of fluorescence intensity was measured for each box within a total of $180 \mathrm{cells} /$ animal/group. The density and small cytoplasm of dentate granule cells precludes the ability to reliably measure signal intensity within individual cells. Instead, the average fluorescence intensity within a rectangular box $\left(\sim 5000 \mu \mathrm{m}^{2}\right.$; six boxes/animal/group) was used to perform a regional analysis of immunofluorescence signal intensity within the dentate gyrus (Fig. 3F-l).

For axonal tau intensity measurements, a $4 x$ objective ( 0.13 numerical aperture) was used to capture two to three images of the dorsal HP in three serial tissue sections per animal. The entire visible regions of the fimbria, alveus, stratum lacunosum, and stratum moleculare were outlined in NIS Elements software. The average fluorescent intensity per area was measured for each axonal region.

\section{Statistical analyses}

All data were analyzed using Prism software (v6.0) and all data are presented as mean \pm SEM. Statistical significance between age groups was determined using oneway ANOVA. Significance was set at $p<0.05$. Tukey's post hoc test was used for post hoc comparisons when significance of $p<0.05$ was reached. If no overall significance was achieved, no post hoc analyses were used.

\section{Results}

\section{Immunoblotting of AIS proteins and tau}

Immunoblots of young, middle, and old age tissue were probed for AIS protein markers, including AnkG, $\beta I V$ spectrin, and neurofascin. When normalized to GAPDH loading controls, no changes were detected between aged groups ( $\beta$ IV-spectrin $F_{(2,12)}=0.1095, p=0.8972$; neurofascin $F_{(2,12)}=0.3654, p=0.7014$; Fig. $\left.1 D, E\right)$. AnkG protein bands were analyzed at 480 and $270 \mathrm{kDa}$ for the AIS-localized AnkG isoforms $\left[F_{(2,15)}=0.03397, p=\right.$ 0.9667 (Fig. 1A); $F_{(2,15)}=0.08969, p=0.9147$ (Fig. 1B); Kordeli et al., 1995; Zhang and Bennett, 1998]. Additional AnkG protein bands were detected at $\sim 190 \mathrm{kDa}$ that did not change with age (data not shown), but these represent other canonical isoforms that are not specific to the AIS (Bennett and Baines, 2001). Blots were probed with SMI312 , an axon-specific neurofilament antibody, to confirm that aging-related axonal loss was not present in the HP. No change in the amount of SMl-312 was detected across age groups $\left(F_{(2,12)}=0.4304, p=0.6599\right.$; Fig. $\left.1 F\right)$.

There was no change across age groups in the levels of total tau protein as indicated by Tau7, a C-terminal pantau antibody $\left(F_{(2,12)}=0.7686, p=0.4852 ;\right.$ Fig. $\left.1 G\right)$. As a secondary method to confirm there were no changes in total tau levels we also probed blots with the R1 tau antibody, a pan-tau rabbit polyclonal antibody $\left(F_{(2,12)}=\right.$ $0.6824, p=0.5240$; Fig. $1 H$ ) and found no aging-related changes (Berry et al., 2004; Horowitz et al., 2006). To determine if specific tau phosphor epitopes were changed with aging in the HP we probed blots with PHF1 antibody and found no differences $\left(F_{(2,12)}=2.361, p=\right.$ 0.1366; Fig.1/). We also probed with the AT8 antibody and the phospho-Ser422 antibody, both of which are diseaserelated modifications of tau (Guillozet-Bongaarts et al., 2006; Jeganathan et al., 2008) and found no signal for either epitope in young, middle or old age animals (data not shown). Tubulin was analyzed to measure the amount of microtubules as a control since tau is a microtubuleassociated protein. There was no change in $\beta$ Ill-tubulin across age groups $\left(F_{(2,12)}=0.8679, p=0.4446\right.$; Fig. $\left.1 J\right)$.

As a positive control for detection of age-related changes of protein, blots were probed for GFAP, a protein previously shown to change in HP lysates of aging rats (VanGuilder et al., 2011). A significant increase in GFAP was found in the old rats compared with the young rats $\left(F_{(2,16)}=4.529, p=0.0276\right.$; Fig. $\left.1 K\right)$. 
A

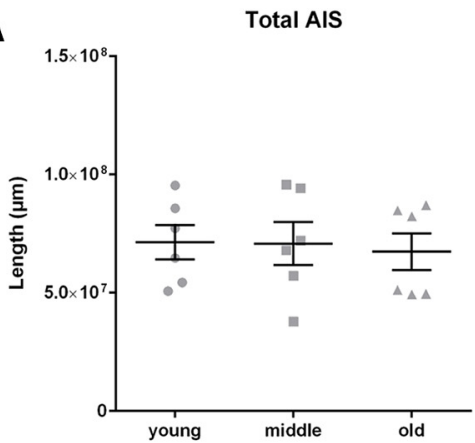

C
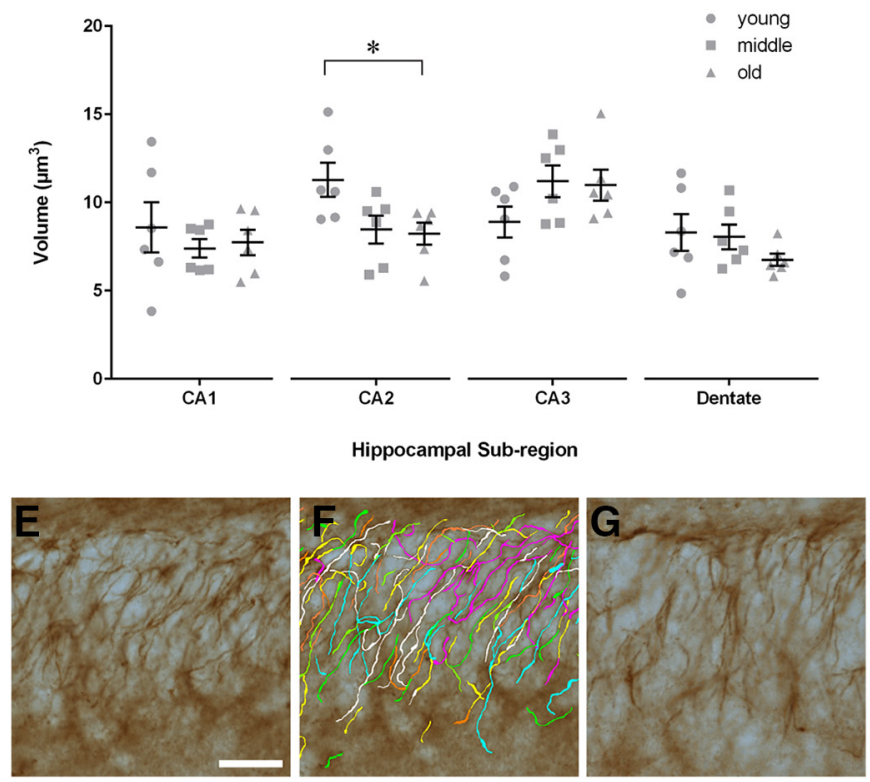

B

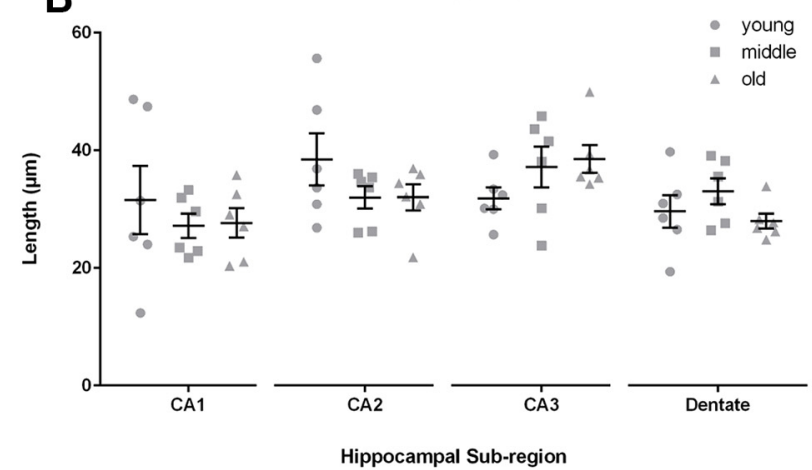

D

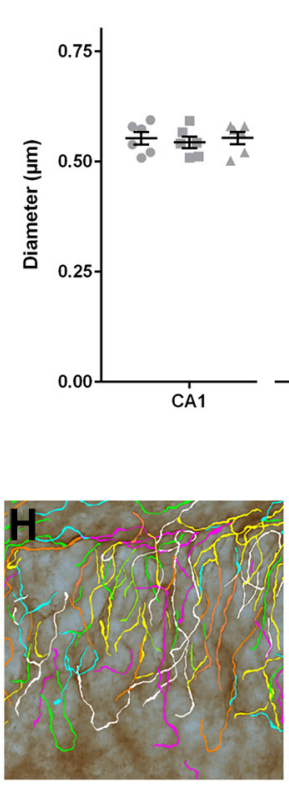

Individual AIS

young

middle

Individual AIS

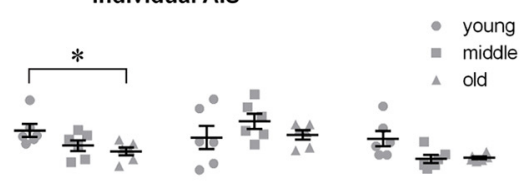

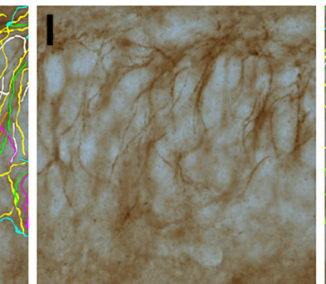

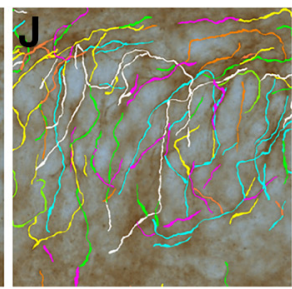

Figure 2. Structural analysis of the AIS with AnkG reveals regional changes in the HP during aging. $\boldsymbol{A}$, The total length of AISs in the HP estimated with the spaceballs stereology probe is unchanged across age groups. $\boldsymbol{B}-\boldsymbol{D}$, The Neurolucida AutoNeuron analysis reveals that the length $(\boldsymbol{B})$, volume $(\boldsymbol{C})$, and diameter $(\boldsymbol{D})$ of the AISs across young, middle, and old aged rats is not changed in CA1, $\mathrm{CA} 3$, or the dentate gyrus of the HP. The volume and diameter of the AISs in the CA2 region were significantly reduced in the old age compared with the young rats (one-way ANOVA, Tukey's post hoc, $* p<0.05$ ). All data are displayed as mean \pm SEM. E-G, Representative images of the AISs (AnkG-positive immunostain, brown) in the dentate gyrus of the HP at ages 4 (E), 14 (G), and 24 (I) months, and the corresponding Neurolucida AutoNeuron tracings $(\boldsymbol{F}, \boldsymbol{H}$, and $\boldsymbol{J}$; multicolor overlay to visually differentiate individual AISs). Scale bar, $20 \mu \mathrm{m}(\boldsymbol{E}-\boldsymbol{I})$.

\section{Stereological assessment of AIS length and morphology}

Stereological analysis of the AIS length (using the spaceballs probe in AnkG-stained tissue) showed no differences in the total length of all AISs in the HP across age groups $\left(F_{(2,15)}=0.07323, p=0.9297\right.$; Fig. $\left.2 A\right)$. We used the AutoNeuron module as a second method to analyze individual AISs in the CA1, CA2, CA3, and dentate gyrus regions of the HP and found that length did not change across age groups in any of these regions (length: CA1: $F_{(2,15)}=0.3940, p=0.6811$; CA2: $F_{(2,15)}=1.488, p=$ 0.2573 ; CA3: $F_{(2,15)}=1.770, p=0.2041$; DG: $F_{(2,15)}=$ $1.413, p=0.2739$; Fig. $2 B$ ). No aging-related change occurred in the volume or diameter of individual AISs in CA1, CA3, or DG (volume: CA1: $F_{(2,15)}=0.3936, p=$ 0.6814; CA3: $F_{(2,15)}=2.077, p=0.1599$; DG: $F_{(2,15)}=$ 1.216, $p=0.3241$ and diameter: CA1: $F_{(2,15)}=0.1559, p$
$=0.8545$; CA3: $F_{(2,15)}=1.061, p=0.3706$; DG: $F_{(2,15)}=$ $0.6705, p=0.5261$; Fig. $2 C, D)$. However, a small but significant change was detected in the volume and diameter of CA2 neurons when comparing young and old animals (volume: CA2: $F_{(2,15)}=4.460, p=0.0302$; and diameter: CA2: $F_{(2,15)}=4.062, p=0.0389$; Fig. $\left.2 C, D\right)$. The measured length of the AIS in HP neurons was $32.86 \pm$ $1.99 \mu \mathrm{m}$ in young, $32.33 \pm 1.379 \mu \mathrm{m}$ in middle, and 31.53 $\pm 1.361 \mu \mathrm{m}$ in old aged animals (Fig. 2B), consistent with previous findings in cultured HP neurons (Grubb and Burrone, 2010; Leterrier et al., 2015).

\section{Optical density measurements of tau levels in somata and axonal layers of the HP}

Optical density measurements of Tau7 immunofluorescence in the somatic compartment of individual HP neurons in tissue sections showed no change across age 

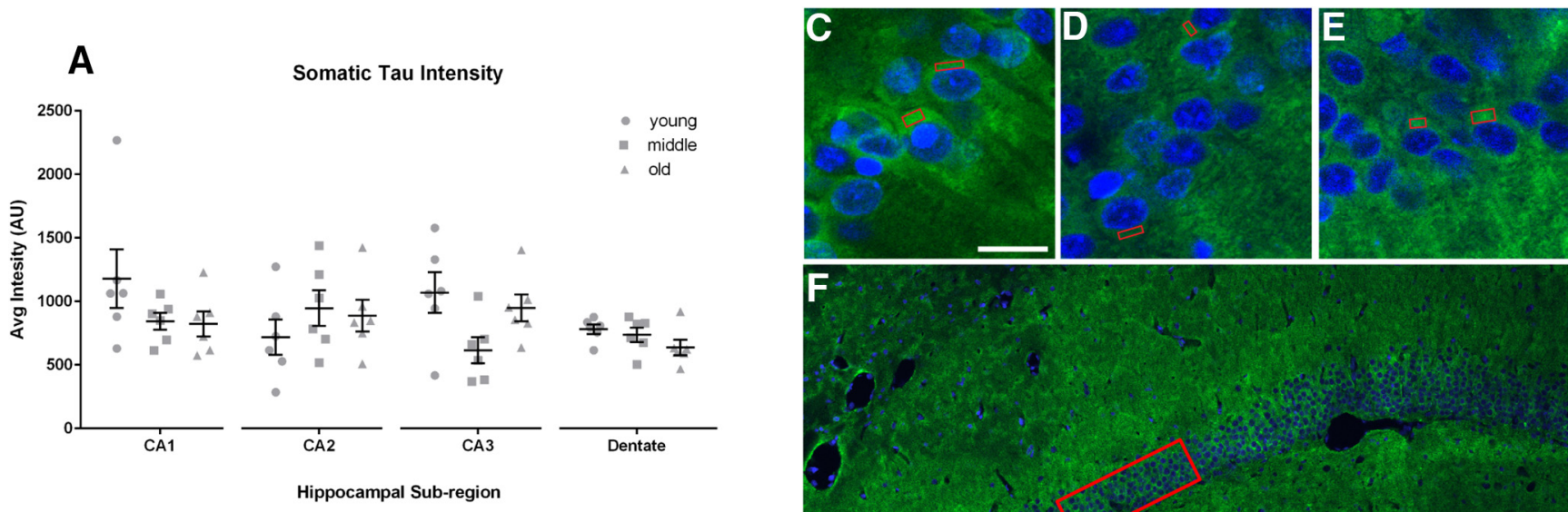

B

Axonal Tau Intensity
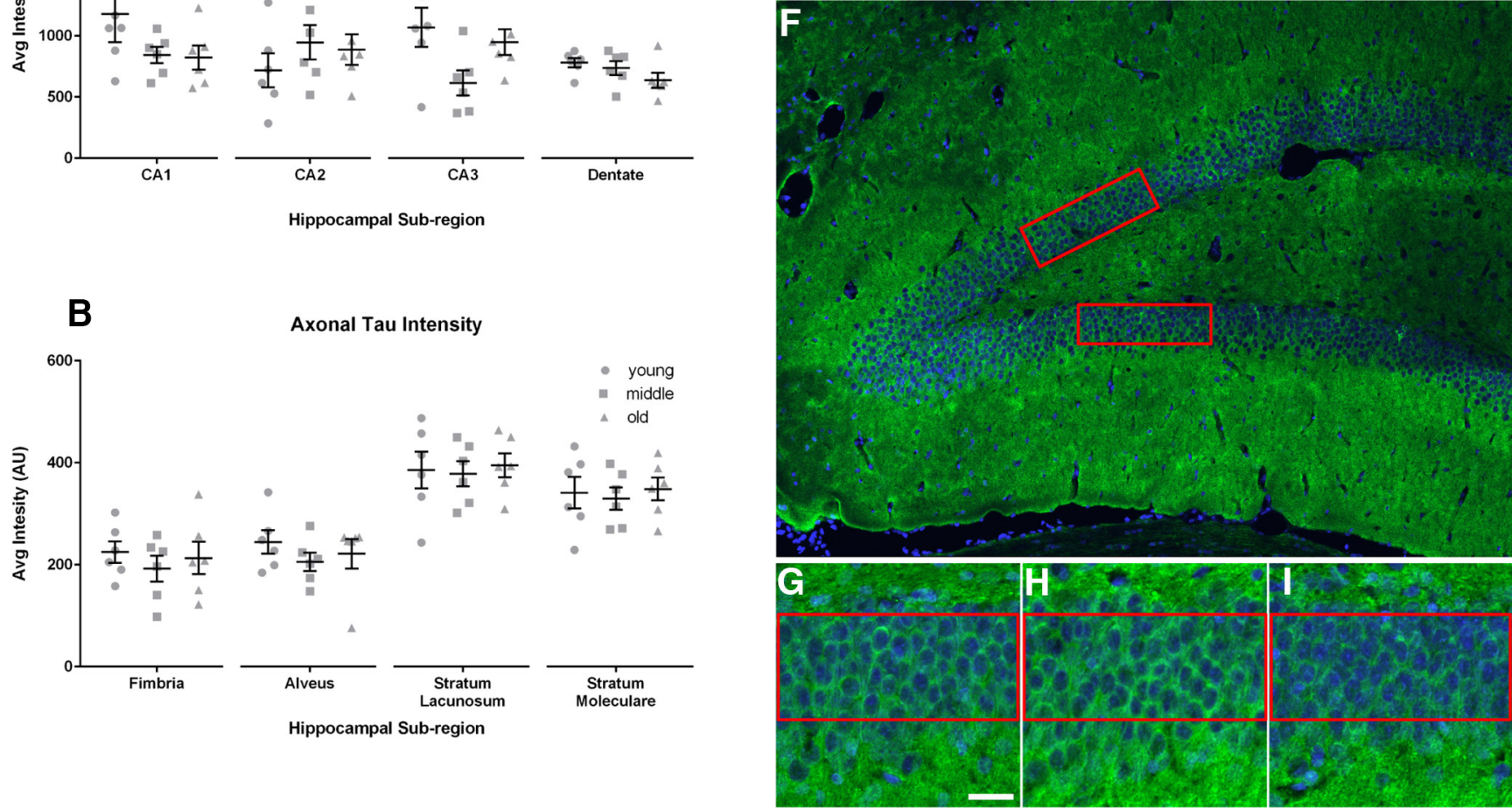

Figure 3. Optical density measurement of tau immunofluorescence in the somata and axons of HP neurons shows no changes across age. $\boldsymbol{A}$, The intensity of somatic tau (using Tau7, a total tau antibody) in neurons in the CA1, CA2, CA3, and dentate regions of the HP shows no change with advancing age. $\boldsymbol{B}$, No change in the regional intensity of tau is detected in the axon-enriched strata of the HP (i.e., the fimbria, alveus, stratum lacunosum, and stratum moleculare). All data are displayed as mean \pm SEM. C-E, Representative images of CA1 HP neurons positive for Tau7 at $4(\boldsymbol{C}), 14(\boldsymbol{D})$, and $24(\boldsymbol{E})$ months. The red rectangles are examples of the areas that fluorescence intensities were measured within individual neurons. $\boldsymbol{F}$, Image illustrating the regions (in red) used for analysis of somatic tau intensity in the dentate gyrus. G-I, Enlargements represent the analyzed regions of 4-month-old $(\boldsymbol{G})$, 14-month-old $(\boldsymbol{H})$, and 24-month-old (I) rats. Scale bar, $20 \mu \mathrm{m}$.

groups (Fig. $3 A$ ). Individual analysis of pyramidal neurons in the $C A$ regions did not show an age-related difference $\left(\mathrm{CA} 1: F_{(2,15)}=1.775, p=0.2033 ; \mathrm{CA} 2: F_{(2,15)}=0.7810, p\right.$ $=0.4757$; CA3: $F_{(2,15)}=3.513, p=0.0561$; Fig. $\left.3 A\right)$, nor did the dentate gyrus show a change in regional intensity with advancing age in rats $\left(F_{(2,15)}=1.924, p=0.1804\right.$; Fig. $3 A$ ). Analysis of tau intensity in HP strata enriched in axonal projections did not detect any change with age (fimbria: $F_{(2,15)}=0.3902, p=0.6836$; alveus: $F_{(2,15)}=$ $0.6694, p=0.5267$; stratum lacunosum: $F_{(2,15)}=0.08560$,

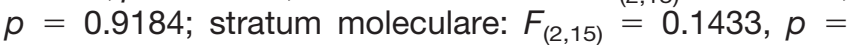
0.8676; Fig. 3B).

\section{Discussion}

With the etiology of $A D$ still unknown, it is important to investigate known risk factors and pathologic changes associated with the disease. The axonal enrichment of tau may deteriorate during the pathogenesis of $A D$ as tau appears to accumulate in the somatodendritic compartment. Considering that aging is the leading risk factor for
$A D$, investigation into the normal aging process may lead to the discovery of previously unappreciated anomalous features that contribute to disease vulnerability. Thus, we investigated the integrity of the AIS, the barrier involved in maintaining axonal localization of tau, over the span of aging in rats to establish whether normal aging might affect the AIS structure and/or tau distribution.

We evaluated age-related changes in tau and the AIS using multiple markers and complementary approaches. However, we found no evidence that the levels of AIS proteins or tau proteins change with age in the HP, nor levels of somatic or axonal tau change in HP neurons with advancing age in rats. The length of the AIS was not found to change in any region of the HP, but a discrete and specific effect was detected in the CA2 region ( $8 \%$ decrease from young to old). The reduction of AIS volume and diameter without a change in length indicates possible atrophy the axonal projections specifically in CA2 neurons, but biological significance of these changes in 
the context of tau distribution and AIS functionality remain unclear. Overall, the findings presented here provide a strong case against aging-related changes in the total tau levels, somatic tau levels, some phosphorylated forms of tau (i.e., PHF1, AT8, pS422), levels of AIS structural proteins (i.e., AnkG, neurofascin, $\beta$ IV-spectrin), or AIS morphology within the HP, thus, these factors are unlikely to contribute to the risk of developing AD. Importantly, these findings do not rule out that other variables related to tau and/or the AIS (e.g., other forms of tau, other characteristics/functions of the AIS, etc.) are changed during normal aging and might contribute to susceptibility for $A D$.

Before this work, a single study assessed the aging changes in the AIS and showed changes in ankyrin and spectrin proteins using Western blottings of telencephalic tissue from aged mice (Bahr et al., 1994). The discordant findings reported here could be due to the use of rats instead of mice, the methods used to immunoblot ankyrin or the increased specificity of antibodies currently available to the isoforms of proteins localized to the AIS (i.e., ankyrin vs AnkG 480/270 kDa or spectrin vs $\beta I V$-spectrin).

Multiple complimentary experimental approaches were used in the evaluation of the effects of aging on both tau and the AIS. Examination of aging-related changes in total tau protein levels was conducted through Western blotting using multiple tau markers, however, these methods do not allow cell-specific measurements. To assess aging-related changes specifically within levels of somatic tau we used fluorescence intensity measurements within the soma of individual HP neurons. Since tau is a microtubule-associated protein, we wanted to establish whether changes in tubulin content was altered with advancing age, but there were no age-related changes in total tubulin levels and the amount of tau per tubulin remained constant within the HP, which aligns well with previous studies showing HP neurons are not lost in normal aging (both in humans and in rats; West et al., 2004; Stanley et al., 2012). These findings demonstrate that the total amount of tau and the amount of tau in the soma remain unchanged in the HP of aging rats.

The same level of rigor was applied to the investigation of the AIS by using a multifaceted approach to evaluate changes in aging rats. Multiple key AIS proteins (AnkG, $\beta I V$-spectrin, and neurofascin) were examined in Western blottings, and we measured SMI312 levels to determine if total axonal content was changed. The lack of aging changes in all AIS proteins assessed and SMI312 suggest that axonal content and key structural components of the AIS are not altered with age. This conclusion is further supported by the lack of changes in tubulin described above. Stereological analysis of the AIS was conducted using two complementary approaches. The space balls probe is an established methodology for detecting agingrelated changes in fiber structures within the brain (Ypsilanti et al., 2008), and here we used it to measure AIS length. The AutoNeuron method in Neurolucida was used to perform 3D measurements of individual AISs and showed a lack of age-related changes in AIS length and only a mild, region-specific decrease in width and volume. This probe has been used previously to measure the diameter of dendrites in pyramidal neurons and compare them across brain regions (Amatrudo et al., 2012).The unbiased stereological measurement of AIS length in the entire HP is a significant advantage of this approach to analyze AIS morphology. The length of the AIS was previously measured with $\beta \mathrm{IV}$-spectrin using a nonstereological method in selected z-stacks of the HP (Baalman et al., 2013). Interestingly, they report that a shortening of AISs correlates to cognitive impairment following explosioninduced brain trauma in Sprague Dawley rats. This work suggests that a shortening of the AIS may correlate to cognitive impairment, but we did not detect a shortening of AISs with age in the current work. Collectively, these data strongly demonstrate that the gross structure of the AIS (i.e., length, diameter, volume) do not change during the normal aging process in most cells of the HP.

Although we are reporting mostly negative data, it is unlikely that the Fischer 344 rat was not an appropriate model of aging to use for this study. We included age groups that span the spectrum from young (4 months), middle (14 months), and old (24 months), which is near the end of the normal lifespan and a time at which agingrelated impairments in memory and cognition occur. For example, an age-related decline in learning ability at 24 months of age was observed using a 14-unit T-maze and shock-motivated one-way active avoidance test in Fischer 344 rats (Spangler et al., 1994). Additionally, 24month-old Fischer 344 rats exhibit pathologies in multiple organ systems associated with advanced aging, further supporting their utility as a model of aging. We confirmed that our techniques and methods are capable of detecting other changes in normal aging that were previously reported (i.e., GFAP increase; VanGuilder et al., 2011).

Several studies showed that there is heterogeneity among aged animals on a number of learning and memory functions (e.g., water maze), as well as other behavioral tasks, indicating that individual animals respond to the aging process differently (Gage et al., 1984; Collier and Coleman, 1991; Freeman et al., 2009). These studies, made it clear that aged animals can be separated into unimpaired or impaired groups based on performance and that these changes correspond to some neurochemical and neuroanatomical changes. However, the data reported here demonstrate that two distinct populations of aged animals do not exist in regard to the specific AIS and tau parameters studied, suggesting these variables do not underlie the behavioral and cognitive decline seen in aging Fischer 344 rats. Analysis of these parameters in young, middle, and old humans may be necessary to definitively establish whether the same holds true for humans.

The negative findings presented here provide important insight into the aging-related changes in tau and AIS in the HP. This information is important considering the contention in the field that tau mislocalization is important in $A D$ and the recent focus on the role of the AIS in tau distribution (Zempel et al., 2010; Li et al., 2011; Sohn et al., 2016). Thus, future investigations should focus on alternative aspects of tau and the AIS to further identify 
whether aging-related changes may contribute to the risk of $A D$.

\section{References}

Amatrudo JM, Weaver CM, Crimins JL, Hof PR, Rosene DL, Luebke JI (2012) Influence of highly distinctive structural properties on the excitability of pyramidal neurons in monkey visual and prefrontal cortices. J Neurosci 32:13644-13660. CrossRef

Baalman KL, Cotton RJ, Rasband SN, Rasband MN (2013) Blast wave exposure impairs memory and decreases axon initial segment length. J Neurotrauma 30:741-751. CrossRef Medline

Bahr BA, Lam N, Lynch G (1994) Changes in the concentrations of tau and other structural proteins in the brains of aged mice. Neurosci Lett 175:49-52. CrossRef

Bennett V, Baines AJ (2001) Spectrin and ankyrin-based pathways: metazoan inventions for integrating cells into tissues. Physiol Rev 81:1353-1392.

Berry JD, Jones S, Drebot MA, Andonov A, Sabara M, Yuan $X Y$, Weingartl H, Fernando L, Marszal P, Gren J, Nicolas B, Andonova M, Ranada F, Gubbins MJ, Ball TB, Kitching P, Li Y, Kabani A, Plummer $F$ (2004) Development and characterisation of neutralising monoclonal antibody to the SARS-coronavirus. J Virol Methods 120:87-96. CrossRef

Binder LI, Frankfurter A, Rebhun LI (1986) Differential localization of MAP-2 and tau in mammalian neurons in situ. Ann NY Acad Sci 466:145-166. Medline

Bolt MW, Mahoney PA (1997) High-efficiency blotting of proteins of diverse sizes following sodium dodecyl sulfate-polyacrylamide gel electrophoresis. Anal Biochem 247:185-192. CrossRef

Buee L, Bussiere T, Buee-Scherrer V, Delacourte A, Hof PR (2000) Tau protein isoforms, phosphorylation and role in neurodegenerative disorders. Brain Res Brain Res Rev 33:95-130.

Caccamo D, Katsetos CD, Herman MM, Frankfurter A, Collins VP, Rubinstein LJ (1989) Immunohistochemistry of a spontaneous murine ovarian teratoma with neuroepithelial differentiation. Neuron-associated beta-tubulin as a marker for primitive neuroepithelium. Lab Invest 60:390-398.

Cochran JN, Hall AM, Roberson ED (2014) The dendritic hypothesis for Alzheimer's disease pathophysiology. Brain Res Bull 103:1828. CrossRef Medline

Collier TJ, Coleman PD (1991) Divergence of biological and chronological aging: evidence from rodent studies. Neurobiol Aging 12: 685-693. CrossRef

Cox K, Combs B, Abdelmesih B, Morfini G, Brady ST, Kanaan NM (2016) Analysis of isoform-specific tau aggregates suggests a common toxic mechanism involving similar pathological conformations and axonal transport inhibition. Neurobiol Aging 47:113126. CrossRef

Davis J, Bennett V (1982) Microtubule-associated protein 2, a microtubule-associated protein from brain, is immunologically related to the alpha subunit of erythrocyte spectrin. J Biol Chem 257:5816-5820.

Fairbanks G, Steck TL, Wallach DF (1971) Electrophoretic analysis of the major polypeptides of the human erythrocyte membrane. Biochemistry 10:2606-2617. CrossRef

Freal A, Fassier C, Le Bras B, Bullier E, De Gois S, Hazan J, Hoogenraad CC, Couraud F (2016) Cooperative interactions between $480 \mathrm{kDa}$ ankyrin-G and $\mathrm{EB}$ proteins assemble the axon initial segment. J Neurosci 36:4421-4433. CrossRef

Freeman WM, VanGuilder HD, Bennett C, Sonntag WE (2009) Cognitive performance and age-related changes in the hippocampal proteome. Neuroscience 159:183-195. CrossRef Medline

Gage FH, Dunnett SB, Björklund A (1984) Spatial learning and motor deficits in aged rats. Neurobiol Aging 5:43-48. Medline

Grubb MS, Burrone J (2010) Activity-dependent relocation of the axon initial segment fine-tunes neuronal excitability. Nature 465: 1070-1074. CrossRef

Guillozet-Bongaarts AL, Cahill ME, Cryns VL, Reynolds MR, Berry RW, Binder LI (2006) Pseudophosphorylation of tau at serine 422 inhibits caspase cleavage: in vitro evidence and implications for tangle formation in vivo. J Neurochem 97:1005-1014. CrossRef

Hedstrom KL, Ogawa Y, Rasband MN (2008) AnkyrinG is required for maintenance of the axon initial segment and neuronal polarity. $J$ Cell Biol 183:635-640. CrossRef Medline

Hedstrom KL, Xu X, Ogawa Y, Frischknecht R, Seidenbecher $\mathrm{Cl}$, Shrager P, Rasband MN (2007) Neurofascin assembles a specialized extracellular matrix at the axon initial segment. J Cell Biol 178:875-886. CrossRef

Horowitz PM, LaPointe N, Guillozet-Bongaarts AL, Berry RW, Binder LI (2006) N-terminal fragments of tau inhibit full-length tau polymerization in vitro. Biochemistry 45:12859-12866. CrossRef

James BD, Leurgans SE, Hebert LE, Scherr PA, Yaffe K, Bennett DA (2014) Contribution of Alzheimer disease to mortality in the United States. Neurology 82:1045-1050. CrossRef Medline

Jeganathan S, Hascher A, Chinnathambi S, Biernat J, Mandelkow EM, Mandelkow E (2008) Proline-directed pseudo-phosphorylation at AT8 and PHF1 epitopes induces a compaction of the paperclip folding of tau and generates a pathological (MC-1) conformation. J Biol Chem 283:32066-32076. CrossRef

Kanaan NM, Kordower JH, Collier TJ (2008) Age-related changes in dopamine transporters and accumulation of 3-nitrotyrosine in rhesus monkey midbrain dopamine neurons: relevance in selective neuronal vulnerability to degeneration. Eur J Neurosci 27:32053215. CrossRef

Kanaan NM, Pigino GF, Brady ST, Lazarov O, Binder LI, Morfini GA (2013) Axonal degeneration in Alzheimer's disease: when signaling abnormalities meet the axonal transport system. Exp Neurol 246: 44-53. CrossRef

Kordeli E, Lambert S, Bennett V (1995) AnkyrinG. A new ankyrin gene with neural-specific isoforms localized at the axonal initial segment and node of Ranvier. J Biol Chem 270:2352-2359. CrossRef

Leterrier C, Dargent B (2014) No Pasaran! Role of the axon initial segment in the regulation of protein transport and the maintenance of axonal identity. Semin Cell Dev Biol 27:44-51.

Leterrier C, Potier J, Caillol G, Debarnot C, Rueda Boroni F, Dargent B (2015) Nanoscale architecture of the axon initial segment reveals an organized and robust scaffold. Cell Rep 13:2781-2793. CrossRef Medline

Li X, Kumar Y, Zempel H, Mandelkow EM, Biernat J, Mandelkow E (2011) Novel diffusion barrier for axonal retention of tau in neurons and its failure in neurodegeneration. EMBO J 30:4825-4837. CrossRef Medline

Oikawa N, Kimura N, Yanagisawa K (2010) Alzheimer-type tau pathology in advanced aged nonhuman primate brains harboring substantial amyloid deposition. Brain Res 1315:137-149. CrossRef

Parhad IM, Scott JN, Cellars LA, Bains JS, Krekoski CA, Clark AW (1995) Axonal atrophy in aging is associated with a decline in neurofilament gene expression. J Neurosci Res 41:355-366. CrossRef

Perez SE, Raghanti MA, Hof PR, Kramer L, Ikonomovic MD, Lacor PN, Erwin JM, Sherwood CC, Mufson EJ (2013) Alzheimer's disease pathology in the neocortex and hippocampus of the western lowland gorilla (Gorilla gorilla gorilla). J Comp Neur 521:43184338. CrossRef

Santuccione AC, Merlini M, Shetty A, Tackenberg C, Bali J, Ferretti MT, McAfoose J, Kulic L, Bernreuther C, Welt T, Grimm J, Glatzel M, Rajendran L, Hock C, Nitsch RM (2013) Active vaccination with ankyrin $\mathrm{G}$ reduces $\beta$-amyloid pathology in APP transgenic mice. Mol Psychiatry 18:358-368. CrossRef

Smiley JF, Bleiwas C (2012) Embedding matrix for simultaneous processing of multiple histological samples. J Neurosci Methods 209:195-198. CrossRef

Sohn PD, Tracy TE, Son HI, Zhou Y, Leite RE, Miller BL, Seeley WW, Grinberg LT, Gan L (2016) Acetylated tau destabilizes the cytoskeleton in the axon initial segment and is mislocalized to the somatodendritic compartment. Mol Neurodegener 11:47. CrossRef 
Song AH, Wang D, Chen G, Li Y, Luo J, Duan S, Poo MM (2009) A selective filter for cytoplasmic transport at the axon initial segment. Cell 136:1148-1160. CrossRef Medline

Spangler EL, Waggie KS, Hengemihle J, Roberts D, Hess B, Ingram DK (1994) Behavioral-assessment of aging in male Fischer-344 and brown-Norway rat strains and their $F(1)$ hybrid. Neurobiol Aging 15:319-328. CrossRef

Stanley EM, Fadel JR, Mott DD (2012) Interneuron loss reduces dendritic inhibition and GABA release in hippocampus of aged rats. Neurobiol Aging 33:431.e1-e13. CrossRef

Sun X, Wu Y, Gu M, Liu Z, Ma Y, Li J, Zhang Y (2014) Selective filtering defect at the axon initial segment in Alzheimer's disease mouse models. Proc Natl Acad Sci USA 111:14271-14276. CrossRef

Tytell M, Brady ST, Lasek RJ (1984) Axonal transport of a subclass of tau proteins: evidence for the regional differentiation of microtubules in neurons. Proc Natl Acad Sci USA 81:1570-1574. CrossRef

van der Staay FJ, Blokland A (1996) Behavioral differences between outbred Wistar, inbred Fischer 344, brown Norway, and hybrid Fischer 344 x brown Norway rats. Physiol Behav 60:97-109.

VanGuilder HD, Bixler GV, Brucklacher RM, Farley JA, Yan H, Warrington JP, Sonntag WE, Freeman WM (2011) Concurrent hippocampal induction of MHC II pathway components and glial activation with advanced aging is not correlated with cognitive impairment. J Neuroinflammation 8:138. CrossRef

West MJ, Kawas CH, Stewart WF, Rudow GL, Troncoso JC (2004) Hippocampal neurons in pre-clinical Alzheimer's disease. Neurobiol Aging 25:1205-1212. CrossRef Medline

Winckler B, Forscher P, Mellman I (1999) A diffusion barrier maintains distribution of membrane proteins in polarized neurons. Nature 397:698-701. CrossRef

Ypsilanti AR, Girão da Cruz MT, Burgess A, Aubert I (2008) The length of hippocampal cholinergic fibers is reduced in the aging brain. Neurobiol Aging 29:1666-1679. CrossRef

Zempel H, Mandelkow E (2014) Lost after translation: missorting of tau protein and consequences for Alzheimer disease. Trends Neurosci 37:721-732. CrossRef

Zempel H, Thies E, Mandelkow E, Mandelkow EM (2010) Abeta oligomers cause localized $\mathrm{Ca}(2+)$ elevation, missorting of endogenous tau into dendrites, tau phosphorylation, and destruction of microtubules and spines. J Neurosci 30:11938-11950. CrossRef

Zhang X, Bennett V (1998) Restriction of 480/270-kD ankyrin(G) to axon proximal segments requires multiple ankyrin(G)-specific domains. J Cell Biol 142:1571-1581. CrossRef

Zhou DX, Lambert S, Malen PL, Carpenter S, Boland LM, Bennett V (1998) Ankyrin(G) is required for clustering of voltage-gated $\mathrm{Na}$ channels at axon initial segments and for normal action potential firing. J Cell Biol 143:1295-1304. CrossRef 